\title{
ENTRE DUAS CRISES, UMA CIDADE. A PRODUÇÃO DO ESPAÇO URBANO DE CAMPINAS, NA PRIMEIRA METADE DO SÉCULO XX.
}

\section{BETWEEN TWO CRISES, A CITY. THE PRODUCTION OF URBAN SPACE OF CAMPINAS, IN THE FIRST HALF OF THE TWENTIETH CENTURY.}

\author{
Edemir de Carvalho ${ }^{1}$
}

\section{Resumo}

Partimos do pressuposto de que, para o estudo de uma situação particular como a de Campinas, haveria necessidade de fixarmos alguns pontos de seu desenvolvimento: o entendimento das crises urbanas, bem como as questões delas resultantes e, por último, o porquê as crises urbanas possuem uma interface com as questões sociais e que, a cada crise, remontam e costuram a complexidade dos problemas urbanos. Pelo menos dois fatos concomitantes sustentam esta posição: a) a formação de uma estrutura urbana, a qual vai se utilizar das "bases urbanas" estabelecidas pela economia apoiada no café, e, ainda, b) a consolidação mercado imobiliário em Campinas. Desse fato, resulta um questionamento importante: se o problema da moradia não se instala subitamente, então cabe desvendar os processos sociais articulam e desenham as crises urbanas e as consequências na produção do espaço urbano de Campinas. Metodologicamente utilizou-se dos estudos historiográficos com base documental, tanto bibliográficos, como arquivos - mapotecas e jornais locais. Como resultado final considera-se que a hipótese da produção do espaço urbano de Campinas foi explicada pela saídas das crises urbanas identificadas.

Palavras-chave: Campinas; Urbanização; Crise urbana; Habitação popular; mercado imobiliário

\begin{abstract}
We assume that for the study of a particular situation like that of Campinas, would need to fixate some points of its development: the understanding of urban crises, as well as issues resulting from them and, finally, why urban crises have an interface with social issues and that every crisis, go back and sew the complexity of urban problems. At least two concomitant facts support this position: a) the formation of an urban structure, which will use the "urban bases" established by the economy resting on the coffee, and also b) consolidating real estate market in Campinas. This fact results an important question: if the housing problem is not installed suddenly, then it is up to unravel the social processes articulate and design the urban crisis and the consequences in the production of urban space in Campinas. Methodologically we used the historiographical studies with documentary base, both bibliographic such as files - maps collections and local newspapers. As a final result it is considered that the hypothesis of the production of urban space in Campinas was explained by the outputs of the identified urban crises.
\end{abstract}

Keywords: Campinas; Urbanization; Urban crisis; Public housing; Real estate market

\footnotetext{
${ }^{1}$ Estagio pós-doutoral Universidad de Castilla-La Mancha (UCLM). Pesquisador Visitante na Universidade Federal de Alagoas - UFAL. Docente da Universidade Estadual Paulista Júlio de Mesquita Filho - UNESP Campus Marília. Avaliador de Instituições de Ensino Superior e de cursos, pelo Instituto Nacional de Estudos e Pesquisas Educacionais Anísio Teixeira - MINISTÉRIO DA EDUCAÇÃO - MEC. E-mail: edemir@marilia.unesp.br
} 


\section{INTRODUÇÃO}

A ideia central deste trabalho reside na compreensão da construção do espaço urbano, através de uma perspectiva sociológica que possibilita alinhavar, historicamente, as diversas questões decorrentes dessa construção, especialmente a habitação. Portanto, a articulação entre essa construção e a produção da habitação emergiu no interior da trama urbana, como resultado de vários processos, que por sua vez articulam-se entre si.

A primeira hipótese explicativa para tornarmos os surtos epidêmicos de febre amarela como manifestação de crise urbana está no fato de que, naquele momento, estávamos diante da formação de uma rede urbana, expressão fenomenológica do insipiente processo de urbanização.

Se a face da crise urbana frente ao capital cafeeiro estava expressa na completa desorganização das atividades urbanas campineiras, a face social atingia diretamente a força de trabalho. O lado trágico da crise estava expresso no morticínio causado pela epidemia, que apressava a fuga de grande parte da população para outras localidades.

A hipótese sustenta-se na ideia de que a febre amarela conduziu a este trágico desfecho porque o espaço urbano chamado Campinas dava conta apenas de propiciar as condições gerais e necessárias à reprodução do modelo primário-exportador, regido pelo café. A força de trabalho urbana pouco significava frente ao capital cafeeiro, ficando à mercê da própria sorte. A epidemia colocou a nu as miseráveis condições a que estava submetida esta força de trabalho urbana em formação.

A transição (1889/1930) que se interpõe entre a primeira crise $(1889 / 1897)$ e a seguinte (1930/1945) esteve marcada pela presença do Estado, na formulação de políticas públicas, invertendo o processo do período anterior, onde a esfera do privado confundia-se com a pública. Nesta transição, além do novo papel do Estado, observa-se o desenvolvimento da força de trabalho urbana.

No primeiro decênio do século XX surgiram as primeiras greves operárias; contudo, elas não possuíam a mesma abrangência daquelas que se produziriam em 1918/19. Estas últimas denunciavam claramente as fissuras no sistema ou os elementos da nova crise que se manifestaria com maior rigor na década de trinta. A segunda crise tem sua primeira manifestação nas greves, dado que estas tinham um caráter muito mais amplo do que apenas as reivindicações salariais: elas estavam denunciando a emergência de uma força de trabalho urbana, a qual não possuía as mínimas condições necessárias para sua reprodução. 
Essa segunda crise caracterizava-se pela articulação de vários processos, os quais deram novos contornos na configuração do espaço urbano campineiro: a emergência de uma força de trabalho, quantitativa e qualitativamente distinta daquela situada no período anterior; o advento de um processo de industrialização e a necessidade de uma maior intervenção do Estado frente às novas questões urbanas apresentadas.

Essas novas questões estavam balizadas pelas solicitações feitas tanto pelo capital quanto pela força de trabalho e fizeram com que essas demandas se traduzissem na necessidade de uma transformação nas formas de organização espacial, particularmente nas formas de apropriação e ocupação do solo urbano.

Tomamos como hipótese que a segunda crise esteve marcada pelo início de um processo de "periferização" da cidade e de renovação urbana, impondo novas formas de apropriação e ocupação do solo urbano. Portanto, a segunda crise encontra sua hipótese explicativa num processo que pode ser entendido a partir de uma visão geral e outra particular: uma diz respeito ao advento do processo de industrialização e outra se processa através dos processos de reorganização espacial.

Ao processo de industrialização, implantado a partir da segunda crise, corresponde, no espaço urbano, uma determinada formação das condições gerais de produção em consonância com o desenvolvimento das relações sociais. É a partir desse pressuposto que podemos entender a produção em massa, nos anos 40 e 50, da habitação popular e a formação das imensas periferias, o que se denomina padrão periférico de urbanização. ${ }^{2}$

Em 1950, o padrão periférico de urbanização já era um fato consumado, pois o processo de industrialização o induziu a uma reorganização espacial ampla, na medida em que, ao processo de expansão urbana correspondia um processo de renovação do centro da cidade.

Campinas possui uma história repleta de fenômenos importantes para o entendimento da questão acima. O cenário campineiro sempre foi privilegiado, devido as condições históricas gestadas em seu território e, particularmente, no que se refere à montagem da sociedade industrial/urbana no Estado de São Paulo. Contudo, partimos do pressuposto de que, para o estudo de uma situação particular como a de Campinas, haveria necessidade de fixarmos dois pontos de seu desenvolvimento: 1. a compreensão do espaço urbano campineiro frente ao

\footnotetext{
2 Ver Badaró, 1986, p. 31.
} 
complexo cafeeiro $^{3} ; 2$. o entendimento das crises urbanas, bem como as questões delas resultantes.

Pelo menos dois fatos concomitantes sustentam a posição da habitação popular como questão social importante, a partir dos anos 20/30: a) o refluxo ou decadência do chamado "complexo cafeeiro" e o advento de um novo período de desenvolvimento econômico baseado na industrialização; b) a formação de uma estrutura urbana, a qual vai se utilizar das "bases urbanas" estabelecidas pela economia apoiada no café, e, ainda, c) a consolidação mercado imobiliário em Campinas.

A forma particular e concreta como Campinas resolveu a sua organização social e territorial, desde os últimos decênios do século passado, revela-nos aspectos essenciais na compreensão da constituição dos seus problemas urbanos, inclusive os atuais.

A economia cafeeira definiu um padrão de acumulação ao qual correspondeu uma organização territorial marcada, entre outras coisas, pela importância de uma rede urbana sustentada por algumas cidades significativas como Campinas, São Paulo, Santos, Rio Claro, entre outras. Neste contexto, Campinas constituía- se num centro regional de vital importância, fato que explica sua espetacular estrutura urbana naquele final de século.

O comércio varejista e atacadista, as pequenas indústrias formavam uma sólida e crescente economia, favorecida pela intensa diversificação dos investimentos realizados pelos cafeicultores.

Toda a espetacular estrutura urbana montada entre 1870 e 1900 foi obra da iniciativa privada, ou seja, a "coisa pública" estava nas mãos da iniciativa privada. Isto só foi possível na medida em que os investimentos urbanos caracterizavam- se como diversificação de investimentos, ou seja, as atividades urbanas, como comércio atacadista, bancos, passaram a representar, juntamente com os serviços educacionais (escolas), hospitais, transporte, novas oportunidades de aplicação dos excedentes de capital propiciados pelo café.

Os planos sanitários foram realizados num largo período, pois, em 1920, ainda existiam obras a realizar. Porém, a partir desta data, haviam novos condicionamentos do crescimento da cidade, justapondo- se aos estímulos da economia cafeeira.

Os investimentos públicos realizados viabilizaram, nos anos vinte, a instalação de várias empresas industriais no município. Contudo, a qualidade de vida dos trabalhadores era péssima. Os baixos salários associavam- se à carestia e à precariedade das habitações populares (cortiços,

\footnotetext{
${ }^{3}$ Ver Harvey, 1978, op. cit.
} 
porões, etc.), formando um conjunto de carências relativas à reprodução da força de trabalho urbana.

Quando adentramos a década de 30, no auge da crise da economia cafeeira, o espaço urbano campineiro já havia assumido novas características, tanto em relação à localização da força de trabalho, quanto em relação a sua organização territorial.

O crescimento do contingente de trabalhadores urbanos, a partir dos anos 30 , conviveu com novos padrões de apropriação e ocupação do solo urbano. Estávamos diante de um processo de "mercantilização" da cidade como um todo.

Nesse período, a formulação do Plano de Melhoramentos Urbanos que se ocupava principalmente do solo urbano, veio a reforçar aquela "mercantilização". Iniciou-se uma reestruturação da organização territorial da cidade, a qual resultou numa reciclagem de pessoas e atividades no espaço urbano.

Poucos investimentos foram realizados no centro desde 1934 até 1945, embora significativos em termos de renovação do centro da cidade, se compararmos com o período pósguerra. Já em 1946, recomeçam os grandes investimentos urbanos, principalmente no que tange à expansão urbana, seja através de novos loteamentos periféricos, seja através da construção de conjuntos habitacionais populares. Iniciou-se um período de "delírio" imobiliário, que perdura até a primeira metade dos anos 50. Desde o final da guerra, até 1953, a área do território urbano foi acrescida em quase 6 vezes (V. tabela 6).

Essa expansão realizou-se com alto custo social para a classe trabalhadora urbana; houve um processo de expulsão de atividades e de pessoas no centro urbano, transferindo os cortiços, colocando como alternativa os novos conjuntos habitacionais na periferia da cidade. Desse modo, as áreas centrais foram liberadas à manipulação do capital imobiliário, com o aval do poder público, através da legislação urbanística consubstanciada no Plano de Melhoramentos Urbanos.

O "boom" imobiliário ocorrido em Campinas, nos anos 1940/50, fez emergir dois aspectos importantes: o advento de um padrão periférico de urbanização, apoiado na intensa expansão do território urbano e num processo de renovação urbana, que se mostraram explicitamente como processos articulados à produção em massa de habitações populares, a qual jogou um papel decisivo neste novo cenário. Entendemos que este fato é de fundamental importância, dado que aqueles processos de renovação e expansão urbana imprimiram uma nova qualidade à questão urbana imposta pelo capital industrial e requalificada pelo capital imobiliário, naquele período. 
Entendemos que o modo pelo qual as condições gerais de produção são gestadas garante uma compreensão dos problemas urbanos dela advindos, ou seja, a dimensão e a qualidade das novas contradições que se formam no espaço urbano.

Nosso interesse centrava-se nos processos de produção da cidade, ou seja, de como esses processos engendram problemas ou contradições, progressivamente mais complexos.

Foi a partir dos conceitos de crise e transição urbana, formulados por Carrion (1987), que superamos este impasse, pois, desse modo, através das crises urbanas e de suas resoluções na transição, percebemos que é possível detectar a constituição dos problemas urbanos, como é o caso da habitação.

O problema habitacional emerge no cenário urbano a partir de determinados condicionamentos, que dizem respeito aos processos de ocupação e apropriação dos espaços urbanos.

Nesse sentido, a compreensão do processo mais geral que desse conta da produção do espaço urbano coloca duas questões metodológicas cruciais: como entender essa produção particular e concreta, a partir de um movimento histórico mais amplo? A segunda questão referese a como compreender as questões que se dão no interior desse espaço urbano, sem perder de vista sua vinculação àquele processo mais geral.

Othake (1982), defende a tese de que "o que se confere ao processo de urbanização é o padrão de acumulação prevalecente numa dada conjuntura histórica". Segundo ela, "cada região e cada cidade, por seu turno, corresponde a uma forma particular e concreta de inserção desta área e de sua população na organização social e territorial que corresponde ao padrão de acumulação prevalecente". ${ }^{4} \mathrm{Se}$, por um lado, a tese de Othake garante com precisão a compreensão da inserção de situações urbanas concretas no movimento histórico mais amplo, de outro lado, ela apresenta incontornáveis inconvenientes, frente aos nossos propósitos, pois, a segunda indagação fica sem resposta.

A nossa proposta para a segunda questão parte da idéia de que os momentos de transformações nos padrões de acumulação, necessariamente induzem a mudanças nas formas particulares e concretas de inserção de cidades e populações na organização social e territorial correspondente ao padrão de acumulação prevalecente. Pensando assim, resta-nos indagar: a partir de qual parâmetro podemos identificar transformações? O parâmetro pode ser identificado com os momentos cruciais dessas transformações.

\footnotetext{
${ }^{4}$ Cf. Semeghini e Pacheco, s/d, mimeo, p. 30.
} 
Sem dúvida, Campinas possui dois momentos cruciais na sua história urbana: o primeiro caracterizado pela estruturação do chamado complexo cafeeiro no "Oeste-Paulista" e, um segundo, marcado pela crise da economia cafeeira e a emergência da industrialização. Esses dois momentos estão assinados por crises urbanas cujas características são completamente distintas: a primeira crise coincide com os surtos epidêmicos da febre amarela, enquanto que a segunda iniciase com o advento do capital imobiliário em Campinas, em 1920.

Os surtos de febre amarela, acontecidos no final do século passado, sugerem, pelas suas evidências, a existência de uma crise urbana, na medida em que a epidemia impôs sérios obstáculos ao desenvolvimento urbano de Campinas, impedindo-a de desempenhar seu importante papel na rede urbana montada pelo complexo cafeeiro, inclusive ameaçando os investimentos realizados pela economia cafeeira nesta cidade.

A primeira hipótese explicativa para tornarmos os surtos epidêmicos de febre amarela como manifestação de crise urbana está no fato de que, naquele momento, estávamos diante da formação de uma rede urbana, expressão fenomenológica do insipiente processo de urbanização.

Se a face da crise urbana frente ao capital cafeeiro estava expressa na completa desorganização das atividades urbanas campineiras, a face social atingia diretamente a força de trabalho. O lado trágico da crise estava expresso no morticínio causado pela epidemia, que apressava a fuga de grande parte da população para outras localidades.

\section{ENTRE DUAS CRISES, UMA CIDADE - CRISE URBANA E AS PRÁTICAS SANITARISTAS}

O período de 1870/1889 esteve assinalado por relações sociais que traduziam o retrato fiel da sociedade em transformação. A rigidez das relações entre os proprietários e os escravos desvanecia-se pela introdução do trabalho livre, via imigração européia maciça. Além disso, o despotismo reinante extrapolou os domínios das propriedades e tentou impor-se então aos recémchegados imigrantes. A sociedade escravista não deixava dúvidas sobre quem era cidadão ${ }^{1}$; num período de mudanças, a questão da cidadania ainda estava atrelada aos interesses e às arbitrariedades dos grandes

Um dos componentes mais importantes do complexo cafeeiro, foi a imigração européia. Sem dúvida, a dinâmica populacional do período de 1870/1935, no estado de São Paulo foi fortemente influenciada pela imigração estrangeira, conforme já verificamos anteriormente.

Nesse largo período, o interregno entre 1886 e 1900, apresenta-se interessante, na medida em que, tanto a imigração torna-se mais intensa, quanto o estado de São Paulo expande 
sua malha urbana, acompanhando a expansão cafeeira, na maioria absoluta dos casos pela fundação de novos municípios. Para o centro urbano campineiro, o período é igualmente significativo, principalmente pela trágica história enfrentada com os surtos epidêmicos.

Segundo Costa (1976), foram transportados pela Companhia Paulista 432.990 imigrantes, entre os anos de 1882 e 1889. No ano de 1888, entraram na província 92.086 imigrantes; destes, 22.223 fizeram baldeação em Campinas e seguiram viagem pela Companhia Mogiana. Instalou-se, nos arredores de Campinas, um expressivo contingente de 42.613 imigrantes.

Esse enorme afluxo de imigrantes representou um potencial imenso de consumo, estimulando o dinamismo e o crescimento do mercado regional, através de intensificação do intercâmbio entre as cidades paulistas.

Tabela 1 - Participação da Rúbrica Saúde e Saneamento no Orçamento do Estado de São Paulo (1892-1920)

\begin{tabular}{|c|c|c|c|}
\hline NO & & NO & \\
\hline 892 & 6 & 907 & 0 \\
\hline 893 & 5 & 908 & 6 \\
\hline 894 & 8 & 909 & 1 \\
\hline 895 & 1 & 910 & 5 \\
\hline 896 & 0 & 911 & 5 \\
\hline 897 & 6 & 912 & 6 \\
\hline 898 & 7 & 913 & 5 \\
\hline 899 & 0 & 914 & 6 \\
\hline 900 & & 915 & 6 \\
\hline 901 & 5 & 916 & 1 \\
\hline 902 & 6 & 917 & 0 \\
\hline 903 & 6 & 918 & 5 \\
\hline 904 & 3 & 919 & 1 \\
\hline
\end{tabular}




\begin{tabular}{|l|l|l|l|}
\hline 905 & & 920 & \\
\hline 906 & 5 & & \\
\hline
\end{tabular}

Fonte: BLOUNT, J. The public health movementi in São Paulo (1982-1918). Tulane University, 1971, p. 199. Apud Nilson, 1985. op. cit.

A partir de 1886, o aumento da imigração deve-se à melhor organização dos cafeicultores, através da Sociedade Promotora de Imigração,e da subvenção que o governo da Província passa a oferecer: essa Sociedade conseguiu financiar a vinda de 30 mil imigrantes em 1887 e, no ano seguinte 100 mil imigrantes, graças aos contratos por ela celebrados com o governo da Província.

Entre 1886 e 1900, a população de Campinas cresce mais de 50\%, ou seja, foram acrescidos aos 41.253 habitantes de 1886, mais 26.341 indivíduos, chegando em 1900 com 67.694 habitantes (V. tabela 4). Considerando que Campinas estava imersa em um surto epidêmico, esse crescimento foi extremamente sensível.

Estas estatísticas populacionais reforçam a crença na eficácia do Plano Sanitário no recondicionamento do centro urbano campineiro. Todavia, a saída da crise proposta pelo Plano e suas praticas sanitárias, não só requalificou o espaço urbano campineiro na sua posição frente à rede urbana regional, como também ensejou uma transição que acentuaria suas contradicoes ${ }^{5}$ internas, através da intensificação da mercantilização e capitalização das suas relações sociais.

Nesse final de século (1870/1900), o trabalho livre era uma necessidade a ser institucionalizada, apoiando-se para isto numa contínua transformação da estrutura produtiva e das suas formas de organização:

1. Foram as cidades que intermediaram as transformações, superando sua dependência produtiva que atrelava sua dinâmica àquela do capital comercial no sistema colonial; impuseram-se como ambiente construído para a produção, ${ }^{6}$ tornando-se sede do trabalho assalariado, articulando novos processos de produção e, consequentemente, de acumulação;

2. A população negra, formalmente livre, somou-se aos densos contingentes de imigrantes europeus, formando, com estes, um excedente de mão-de-obra urbana;

\footnotetext{
${ }^{5} \mathrm{O}$ sistema de objetos imobiliários é a expressão física da formação do valor complexo de uso (ver Ribeiro, 1982). (Ver nota 24).

${ }^{6}$ Ver Harvey, 1978, op. cit.
}

Revista de Direito da Cidade, vol. 08, no 2. ISSN 2317-7721 pp.587-610 595 
3. O crescimento industrial, em que pese inicialmente seu atrelamento à expansão especifica da cultura cafeeira, passou à responder às necessidades do complexo como um todo. Suspiram as indústrias, em parte, necessidades do mercado, agora também urbano, e introduziram-se como segmento econômico gerador de riquezas. Porém, eram indústrias tributárias do padrão de acumulação dado pela dinâmica do café;

4. Por último, a indústria caracterizou-se pela multiplicidade de pequenas empresas, cujo tamanho estava delimitado, rigidamente, pelos reduzidos mercados locais, aos quais estava atrelada e dos quais era dependente. ${ }^{7}$

Em Campinas e região, são poucas as empresas com grande número de operários, pelo menos até $1910 .{ }^{8}$

Pelo censo de 1907, com todas as incorreções que apresentou, podemos observar que existiam quatro grandes empresas industriais em Campinas: “A Usina Esther (Cosmópolis), com 200 operários, a tecelagem Carioba (Americana) com 253 operários, a Cia Campineira de Carris de Ferro (oficinas com 87 operários) e a Cia Mac Hardy, metalúrgica, com 254 operários, produtora de máquinas e implementos agrícolas (setor que contava com mais 3 empresas, com 102 operários)". ${ }^{9}$

Estimuladas pelo crescente mercado, no final do século XIX e na primeira década do século $X X$, surgem inúmeras empresas, principalmente de alimentos e de tecidos (de massas alimentícias, cervejarias, têxteis, de artigos de couro e de sabão).

Em 1908, instala-se, em Campinas, a cervejaria Columbia e, em 1910, a Companhia Curtidora Campineira.

A população campineira cresceu com mais intensidade até os anos iniciais da década de 1910, acompanhando as super-safras de 1911 e 1912. Os estabelecimentos comerciais e fabris também crescem neste período e, posteriormente, entram num rítmo menor de crescimento até os anos 20 e 30. Naturalmente, a economia sustentou-se devido ao intervencionismo do governo em relação à exploração de produtos primários, cujos maiores beneficiários sempre foram os cafeicultores, e, obviamente, todos aqueles que compunham o chamado complexo cafeeiro.

\footnotetext{
7 Silva, 1981, discute a industrialização brasileira, e com base nas estatísticas de 1907, sugere a revisão da tese segundo a qual a indústria caracterizava - se por empresas voltadas para reduzidos mercados locais. De fato, a indústria têxtil do período é considerada moderna para a época.

${ }^{8}$ Apesar de pequenas, as atividades manufatureiras até aqui denominadas fabris, possuíam alguma divisão técnica do trabalho, pois a presença de um contramestre evidenciava tal fato. Acrescente-se que o contramestre não era proprietário.

${ }^{9} \mathrm{Cf}$. Semeghini e Pacheco, s/d, mimeo, p. 30.
} 
É inconteste que Campinas já havia contemplado, nas duas primeiras décadas deste século, um ambiente construído para a produção, essencialmente, e, secundariamente, para o consumo.

Uma nova arrancada no desenvolvimento em Campinas, devido à epidemia de febre amarela, foi retardado até os anos trinta deste século. Badaró (1986) comenta, em sua tese, que a partir de 1910 o comércio não apresentava o mesmo vigor, inclusive já havia sinais de enfraquecimento da sua privilegiada posição de grande centro distribuidor e financeiro (distribuidor e produtor de manufaturados e agenciador de financiamentos voltados aos novos projetos na agricultura). Entre 1910 e 1920, o comércio já não apresentava a sua amplitude regional, chegando próximo à estagnação. Sua sobrevivência foi sustentada às custas dos sistema de crédito, implantado em 1911. ${ }^{10}$

Se até 1912 houve um crescimento, os anos seguintes não tiveram a mesma sorte. A partir de março de 1913, o jornal Comércio de Campinas estampou grandes manchetes encabeçando enormes artigos comentando e protestando contra a carestia. Em setembro deste ano, o jornal Diário do Povo publicou artigos comentando a grave crise econômica que afetava agricultura, indústria e comércio, destacando que as falências eram em numero crescente. Em janeiro de 1914, o mesmo Diário do Povo, abordando "a pavorosa crise", denunciou o fechamento de fabricas e os 500 desempregados que existiam na cidade.

A década de 1920 vai fazer de Campinas uma cidade inserida num novo patamar de industrialização, isto é, ramos industriais mais dinâmicos instalam-se no município, acompanhando o ritmo da capital do estado.

A diversificação da agricultura provoca mudanças nas relações com a indústria, criando juntamente com este setor uma nova estrutura urbana. Portanto, a diversificação e expansão da agricultura e da indústria articulam- se com a rede urbana, fazendo desta uma imensa malha seletiva de atividades produtivas, bem como influenciando na distribuição da população, mobilizando-a em direção aos centros mais urbanizados (coincidentemente mais industrializados). ${ }^{11}$

Segundo o recenseamento do Brasil de 1920, o Estado de São Paulo contava com 83.998 operários e Campinas detinha 7\% deste total. A população do município, nessa data, era de 115.602 habitantes, 2,5\% da população do Estado de São Paulo.

\footnotetext{
${ }^{10}$ Ver Badaró, 1986, p. 31.

${ }^{11}$ Ver Faria, 1978 e Othakae, 1982, op. cit.
} 
A correlação entre o afluxo de mão-de-obra e a implantação da industria é direta, o município se urbaniza enquanto o processo de industrialização avança. ${ }^{12}$

Desde a década de 1920 que Campinas revigora seu parque industrial. Portanto, a presença da indústria no município já era expressiva, mesmo antes do surto de industrialização que toma impulso em 1930. Todavia, nesse período de transição, seu perfil industrial ainda é análogo ao do restante do Estado, distinguindo-se apenas pelo porte ou por já possuir algumas plantas industriais ligadas a setores mais dinâmicos.

Em que pesem as transformações em curso na economia brasileira, vale mencionar que algumas ações locais contribuíram para o impulsionamento das mudanças, como é o caso da Resolução 600 (ver anexo) proposta pelo Vereador Álvaro Ribeiro, em 21 de dezembro de 1920, junto à Câmara Municipal. Esta resolução permitiu a Silvino de Godói a instalação de sua Fábrica de Tecidos Elásticos de Godoy e Valbert pela concessão de isenções tributárias pelo período de dez anos.

A Resolução 600 estimulou a instalação ou permanência de muitas empresas no município, dentre as quais destacam-se:

1. No setor têxtil: a Chapéus Cury; a Seda Nacional, posteriormente pertencente às Indústrias Reunidas Matarazzo; as Tecelagens Nossa Senhora Auxiliadora, Princesa d'Oeste, Sant'Ângela, São Jorge, Seda Santa Adélia, Sedas Auri-Verde, Stella, Universo, Urca, Companhia Moreira de Padronização;

2. No setor metal- mecânico: Industria Brasileira de Artefatos de Ferro - IBAF -, a primeira na América do Sul a produzir ferro maleável; Fábrica de Fogões Dako; Fábrica de Fogões Paterno; Correntes Menke S/A;

3. Outras fábricas importantes como: Cortumes Fermino Costa e Cantúsio: Fábrica de Papéis e Papelão Campinas; Fábrica da Companhia Swift; Fábrica Durex; as Cerâmicas Ortolan, Santa Luzia e Sumaré.

Além disso, essas indústrias aqueceram o mercado de trabalho, fazendo com que a demanda por mão-de-obra no município praticamente dobrasse, pois entre 1928 e 1937 o número

12 "A estatística de 1928 mostra que foi vigoroso o impulso indústrial da década de 20, em Campinas, implantavam -se dois grandes estabelecimentos para produzir tecidos de seda (790 operários), uma fábrica de lápis (Johann Faber - 1000 operários), a fábrica de chapéus Cury, Cortume, Fábrica de sabão e sabonetes (2 estabelecimentos, 173 operários) e uma fábrica de caixas de papelão (117 operários). No segmento metalmecânico, cujo núcleo básico se constituía de fábrica de máquinas e implementos agrícolas e das oficinas das estradas de ferro, o destaque no período é o crescimento da oficinas e pequenas empresas de reparação para autos e caminhões". (Semeghini e Pacheco, s/d., mímeo, p. 20.). 
de estabelecimentos e de pessoal ocupado aumentou vertiginosamente. Nesse período, o pessoal empregado na indústria passou de 4100 para 9700 operários, um aumento de quase $140 \%$. Quando se compara com os dez anos seguintes, ou seja, até 1948, o aumento não foi tão avantajado como naqueles primeiros dez anos: de 1937 a 1948 o número de operários fabris aumentou em apenas 1762, isto é, de 9700 operários, em 1937, passou para 11.462, em 1948, o equivalente a apenas 18\%. Há que se pesar, nessa evolução, o período da II Guerra Mundial. Ele é tão significativo que o peso dos diversos ramos industriais nas estruturas ocupacionais, entre 1937 e 1948, praticamente não se alterou. Porém, há que se ressaltar que as empresas multinacionais (Rhodia, Rigesa, 3M, Duratex), foram aqui instaladas por volta de 1942, e não haviam iniciado ainda um processo mais intenso de relações intersetoriais. Entre os anos 1948 e 1956, Campinas era o quarto centro industrial de São Paulo.

Sem dúvida, essas indústrias impuseram uma nova estrutura econômica, cujo resultado foi um aprofundamento na divisão social do trabalho. Elas não só indicavam novas relações técnicas de produção, como também estabeleceram novas relações sociais qualitativamente diversas. A presença de um contingente de trabalhadores cada vez maior, condicionava diferentemente suas relações, não só em relação às necessidades do capital monopolista, mas, principalmente, quanto às possibilidades das práticas de altas taxas de exploração do trabalho ou de formas espoliativas, confundindo-as com a condição urbana de subsistência, tal a extensão da sua atuação sobre amplas parcelas do operariado urbano.

A indústria imprimiu uma dinâmica populacional reorganizadora da distribuição da população, especialmente nos centros urbanos industrialmente desenvolvidos.

Pode-se entender que a indústria estava redefinindo o mercado de trabalho urbano, ainda que pouco organizado. Todavia, a vida da classe trabalhadora urbana em pouco ou nada se alterava. Tomando por base a situação em outros municípios - as condições de Campinas dificilmente seriam diferentes -, sabe-se que a classe trabalhadora sempre arcou com o pesado ônus de um custo de vida cada vez mais alto, o que contribuiu para a proliferação de cortiços e das pensões precaríssimas e a transformação de porões e vagões ferroviários em moradia.

Estiveram presentes, neste contexto urbano, novos conflitos, ainda que mal delineados e facilmente visíveis em algumas manifestações, e a iniciativa, estatal ou privada, sempre visou diluílos em ações paliativas: não foram poucas as associações beneficentes e de auxílio mútuo, nas quais os trabalhadores participaram. Era através dessas organizações que os trabalhadores já se faziam presentes com suas reivindicações de melhoria das péssimas condições de vida. 
Os conflitos estavam rascunhados naquele mosaico social dos primeiros 30 anos deste século; as condições só emergiram, plenamente amadurecidas, após os anos 30, quando a eminência do novo padrão de acumulação explicitou novas contradições.

Os anos vinte foram cruciais para o complexo cafeeiro, pois tornara-se insustentável ignorar os problemas, especialmente os urbanos ou aqueles que explodiam no ambiente urbano. As suas manifestações se faziam de maneira incisiva através das greves, concentração de cortiços, entre outros constrangimentos.

\section{UMA NOVA CRISE}

A segunda crise urbana esteve configurada sob os limites de dois aspectos gerais: o primeiro aspecto diz respeito à superação da forma de organização territorial urbana, dada pelo padrão de acumulação do complexo cafeeiro, especialmente nos seus aspectos de ocupação e apropriação daquele território; o segundo refere-se à produção das condições gerais da produção correspondente ao processo de industrialização.

Observa-se a estruturação de uma nova organização espacial: Campinas, até os anos 20, não possuía bairros periféricos, tais como aqueles surgidos na segunda metade dessa década, bairros estes que constituíam os primeiros sinais da segunda crise urbana. Foi uma crise radicalmente distinta daquela primeira, em que a intervenção ao nível dos equipamentos de infraestrutura, pelo Estado, deu início a uma transição que perdurou até 1930. Nesse momento, a crise urbana assumia múltiplas dimensões: se, de um lado, os bairros periféricos anunciavam a expansão urbana, de outro, o protesto popular, através das greves e outras manifestações públicas, evidenciavam a dimensão social do conflito urbano naqueles anos.

Em 1930, a crise já não era um prenúncio, o complexo cafeeiro enfrentava a crise definitiva, cedendo terreno a uma transformação econômica e social, na qual estava incluso o processo de industrialização, bem como uma radical transformação do ambiente urbano construído.

Nessa segunda crise urbana, a transição estava voltada para a implantação de um ambiente construído cuja característica primordial era a articulação de uma estrutura urbana adequada ao processo de industrialização. É por isso que, diferentemente da primeira crise, agora Campinas necessitava, emergencialmente, da manutenção do nível de concentração dos meios de consumo coletivo, do comércio atacadista e das indústrias da cafeicultura, aquelas que fabricavam implementos agrícolas.

Revista de Direito da Cidade, vol. 08, no 2. ISSN 2317-7721 pp.587-610 600 
A economia cafeeira, comandada pelo capital cafeeiro, impunha uma divisão social do trabalho, na qual a cidade de Campinas dispunha de uma posição privilegiada e de grande influência, frente às principais regiões produtoras de café. Portanto, a superação da primeira crise urbana campineira significou a manutenção de níveis adequados da produção na região.

As transformações eram generalizadas e anunciavam, de um lado a decadência do café e, por outro, a emergência da industrialização. Campinas, um município tradicionalmente cafeeiro, apesar de ter montado uma espetacular infraestrutura, estava a exigir novas condições urbanas para que a indústria pudesse se desenvolver.

Desse modo, dois fenômenos, com potencial transformador, estavam em curso ativo no município: a expansão e valorização das terras urbanas, bem como o processo industrializante, garantido pela implantação de várias unidades industriais.

Estava-se diante de uma nova e diferente crise. Esta crise continha questões exigindo radicais transformações no antigo padrão de organização territorial, expresso na apropriação e ocupação do solo urbano. A crise desenhava-se de cunho essencialmente capitalista, pois seu ponto nevrálgico estava no paulatino fortalecimento capitalista da cidade, com base numa acumulação industrial e urbana. ${ }^{13}$

Esse processo de capitalização da cidade passava pela transformação dos proprietários rurais em urbanos, pela formação de um mercado imobiliário, primeiramente baseado na expansão, via loteamentos dos sítios e fazendas próximas à cidade e, posteriormente, pelo desenvolvimento da indústria da construção civil, intimamente associada à expansão dos loteamentos e à renovação do centro urbano.

Os loteamentos e a instalação das novas e dinâmicas fábricas em Campinas provocaram vários problemas em relação ao antigo padrão de ocupação do seu espaço urbano. Não havia critérios muito rígidos quanto a localização dessas indústrias e logo viu-se a cidade envolvida pela expansão urbana, que causava problemas quanto à própria reorganização territorial, no período seguinte. Além disso, segundo Badaró, "os novos loteamentos, projetados pelas companhias imobiliárias e submetidos à aprovação da municipalidade não obedeciam, muitas vezes, aos critérios técnicos e muito menos a um planejamento geral (...). Surgiram problemas de ligação viária dos novos bairros entre si e com o centro da cidade, visto que muitos deles se situavam fora

\footnotetext{
${ }^{13}$ A diferença dessa nova crise não está no fato de ser essencialmente capitalista, uma vez que a anterior possuía esta característica, mas sim no fato de que agora o centro da acumulação capitalista é, concomitantemente, industrial e urbano. Este fato implica na formulação de uma tendência em relação aos problemas: eles passam pelas relações elaboradas no espaço urbano ou são urbanos.
} 
do perímetro urbanizado e outros apresentavam acentuadas descontinuidades com a malha urbana existente" ${ }^{14}$

Um outro tipo de problema também se colocava no interior desta nova crise urbana; problema, aliás, de dupla face, com que se defrontava a Prefeitura: o recondicionamento das velhas infra-estruturas, produzidas com os planos sanitários, e sua compatibilização com as novas, surgidas como resultado da expansão em curso. ${ }^{15}$

Até 1930, o complexo cafeeiro fez de Campinas um ambiente construído onde estavam presentes um sistema de objetos imobiliários, ${ }^{16}$ cuja a tarefa era fazer com que aquele ambiente viabilizasse o processo global de produção. Sendo assim, para o complexo cafeeiro eram de importância regional determinados centros urbanos, articuladores da rede urbana. O sistema de objetos imobiliários existentes em Campinas, até 1930, respondia, dessa maneira, às necessidades da produção e circulação de mercadorias a nível regional.

É através desta constatação que a segunda crise urbana vai marcar sua diferença em relação à primeira: a constituição de novos marcos das relações capitalistas e o processo de industrialização davam ao espaço urbano campineiro um inédito e importante papel no processo de acumulação que se definia. A partir daquele momento, a concentração espacial de um grande número de trabalhadores, a instalação de um grande número de variadas indústrias, bem como de um sistema financeiro e do desenvolvimento de um comércio e de serviços impuseram, a nível local, novas necessidades quanto à divisão econômico-social do espaço. ${ }^{17}$

Essas novas características traduziram uma brutal inversão no lócus da produção: o espaço urbano passa a ser esse lócus. Para que isto acontecesse, foi necessário que o espaço urbano se promovesse enquanto valor de uso complexo ${ }^{18}$ e interiorizasse de modo definitivo a disputa intercapitalista. Estes fatores impuseram progressivamente um duplo processo no interior da cidade: de um lado, a concentração de atividades sociais e econômicas e, de outro, uma nova

\footnotetext{
${ }^{14}$ Cf. Badaró, 1986, p. 37.

15 Badaró descreve esta questão da seguinte maneira: "o antigo e já precário sistema de abastecimento d'água tornou - se incapaz de suprir a demanda dos terrenos elevados do Jardim Guanabara e Chapadão. Necessidades de esgoto, obras viárias, pavimentação e transportes haviam colocado a Prefeitura a reboque da indiscriminada expansão dos loteamentos que avançam então, muito além da demanda efetiva" $V$. Badaró, 1986, p. 37.

${ }^{16}$ O sistema de objetos imobiliários é a expressão física da formação do valor complexo de uso (ver Ribeiro, 1982). (Ver nota 24).

17 V. Lipietz, 1982.

18 para Lojkine, 1981, os valores de uso complexo, dificilmente divisíveis, duráveis, imóveis, os meios de consumo coletivos, têm a característica de não se coagularem em produtos materiais separados, exteriores às atividades que os produziram.
}

Revista de Direito da Cidade, vol. 08, no 2. ISSN 2317-7721 pp.587-610 602 
relação entre o espaço urbano e a produção de mercadorias, uma vez que a apropriação, pelo capital, dos efeitos úteis da aglomeração, exigia o trabalho social mais produtivo e de mais valia. ${ }^{19}$

Estes dois processos, acima referidos, encontraram em Campinas sérios obstáculos à sua consecução espacial. Pois a velha e rígida estrutura urbana conflitava com a necessidade de uma nova organização do espaço urbano.

Quando os primeiros bairros periféricos começaram a surgir em Campinas, nos anos 20, apareceram também os conflitos entre a velha infraestrutura física pré-existente com as novas exigências do capital, no que tange à apropriação dos efeitos úteis da aglomeração. Portanto, a necessidade de expansão urbana estava muito mais atenta ao processo de renovação urbana do que a atender a uma possível crise de demanda por novos espaços residenciais.

Assim, emerge no cenário urbano uma nova crise caracterizada pelos processos de renovação e de expansão urbana, que impôs o Estado como viabilizador da nova estrutura urbana subordinada àqueles processos.

No final dos anos 20 tornou-se evidente a mobilização dos interesses imobiliários. ${ }^{20}$ Não é só a atuação das imobiliárias e/ou proprietários que produz essa mobilização. Os discursos dos políticos locais e de pessoas e/ou entidades ligadas ao setor também fazem seus interesses transparecerem. Em 1929 o Prefeito Orozimbo Maia dirige-se, através de ofício, à Câmara Municipal, sugerindo a elaboração de um plano. Neste mesmo ano foi mantido "entendimento com o engenheiro Anhaia de Mello, professor de urbanismo da Escola Politécnica de São Paulo, visando a elaboração de um plano de expansão para a cidade (...). Em 1931, criou-se a Comissão de urbanismo (...) o assunto voltou à baila, desta feita, com o tema de uma palestra proferida pelo eminente engenheiro Carlos W. Stevenson, no Rotary Club de Campinas". ${ }^{21}$

É dentro desse cenário que a expansão territorial urbana ensejou a formulação de um plano urbanístico, cuja proposta sintetizava as questões expostas pela crise

Badaró afirma que a proposta do plano urbanístico para Campinas estava atrelada a três fatores:

1. Em primeiro lugar, menciona as repercussões econômicas e físico territoriais, decorrentes do desenvolvimento industrial, quais sejam: a intensificação do processo de urbanização, a

\footnotetext{
${ }^{19}$ Ver Ribeiro, 1982, op. cit.

20 Entende-se por interesse imobiliário, todo aquele que diz respeito ao mercado de terras urbanas e à construção civil. È difícil separar esses interesses, apesar de apresentarem características peculiares. São eles faces da mesma moeda, pois é praticamente impossível pensá-los em separado.

${ }^{21}$ V. Stevenson, 1934.
}

Revista de Direito da Cidade, vol. 08, no 2. ISSN 2317-7721 pp.587-610 603 
valorização dos terrenos existentes e a grande expansão da área urbana edificável, ocorridas a partir dos anos 20 sob os auspícios da especulação imobiliária...;

2. Em segundo lugar, influenciaram na contratação do plano urbanístico fatores decorrentes da febre amarela... O binômio higiene e saneamento, que frequentava os programas políticos das autoridades municipais, aflui naturalmente para a proposição de um plano de urbanismo, quando o crescimento populacional e territorial se torna mais intenso...;

3. Finalmente, iriam-se associar-se a estes dois primeiros fatores, outros, de significação cultural, que caracterizavam o campineiro da época. Eram: o orgulho pela cidade - o bairrismo - e o bom nível intelectual de sua elite dominante, ambos herdados sobretudo do período cafeeiro, quando Campinas era considerada por muitos a capital agrícola do Estado e era designada, amiúde, por capital intelectual de São Paulo.

Sem que se discorde dos fatores motivadores do Plano de Melhoramentos Urbanos, sugeridos por Badaró, acredita-se que, por si só, eles são insuficientes para dar conta de toda explicação. Seus argumentos escondem as razões mais profundas da mudança do território urbano da época, já observadas.

A proposta de formulação de um plano urbanístico foi, incontestavelmente, um instrumento poderoso nas mãos do poder público local. Pois, ao mesmo tempo em que ordenaria o solo urbano, propiciaria uma especialização desse território, garantindo vantagens adicionais aos futuros investimentos.

Assim, a "intensificação do processo de urbanização, a valorização dos terrenos existentes e a grande expansão da área urbana edificável", bem como "o binômio higiene e saneamento" foram fatores que, na verdade, estavam por evidenciar que a transformação de base produtiva do agrário para industrial urbano implicava, também, no redimensionamento dos meios de consumo coletivo, com vistas à exigência do novo padrão de urbanização e, consequentemente, a "um novo tipo de socialização das condições gerais da produção". ${ }^{22}$

Diante desse quadro, o "bairrismo", qualquer que tenha sido seu peso, e a preocupação com a higiene e o saneamento, foram fatores que se articularam aos interesses do capital imobiliário urbano. ${ }^{23}$ Portanto, esses fatores apresentaram-se como manifestações de cunho ideológico inseridas num processo social mais amplo.

\footnotetext{
${ }^{22}$ V. Lojikine, 1981, op. cit.

${ }^{23}$ Ver Lessa, s/d, mimeo.
}

Revista de Direito da Cidade, vol. 08, no 2. ISSN 2317-7721 pp.587-610 604 
O reconhecimento desse processo implica também em reconhecer a existência de outros condicionamentos sociais, tais como: o fortalecimento do operariado urbano, via incremento do seu contingente e da sua organização; a instalação de novas unidades produtivas no município requisitando uma ampliação ou renovação da infra-estrutura existente; um mercado de trabalho que impunha uma proletarização em que o trabalhador urbano via-se completamente envolvido pela miséria.

Foram, de certo modo, estas condições embutidas na primeira crise (febre amarela), que dizimaram boa parte dos miseráveis residentes na cidade. Agora, nesta segunda crise, a proposta de elaboração de um plano urbanístico assumiu um caráter de legitimador das condições precárias a que estava submetida a maioria da população.

Esta legitimação aparece de maneira subentendida nas propostas dos planos apresentados: a referência é sempre em relação à tendência a ser uma grande cidade, "talhada para ser um centro industrial privilegiado pela situação e vias de comunicação". ${ }^{24}$ Quando o engenheiro Carlos Stevenson proferiu sua palestra no Rotary Clube de Capinas, em 1933, a mesma idéia estava presente no seu discurso: "e todos nós, Campineiros natos e de adoção, queremos ver esboçado o plano da nova cidade, a Campinas de Amanhã, que possa abrir aos visitantes os solares da hospitalidade, pelas portas largas de bem traçadas avenidas, cheias de ar, de luz, de elegantes prédios e bons edifícios públicos". ${ }^{25}$ Além disso, este engenheiro apresentou, nessa mesma palestra, a proposta de um sistema viário básico para Campinas (ver mapa 2).

A idéia de expandir a cidade ou de abrir ruas e avenidas e construir novos prédios, estava diretamente relacionada aos interesses dos proprietários de terras ou aos interesses da indústria da construção civil. ${ }^{26}$ Nesse momento de crise da economia cafeeira, tornou-se interessante não só a transformação de proprietário rural em urbano, como também investir na construção civil. São formas de transferir capital de um ramo para o outro sem a necessidade de dispor de grande volume de recursos.

Alguns proprietários rurais já haviam tomado a iniciativa de lotear algumas propriedades fora do perímetro urbano (bairros do Bonfim, Vila Teixera, Parque Industrial, etc.). Como já foi observado, estes loteamentos estavam desprovidos de qualquer equipamento urbano, pois não

\footnotetext{
${ }^{24}$ Ofício do Prefeito Orozimbo Maia enviado à Câmara Municipal (apud Badaró, 1986, op. cit.).

${ }^{25}$ Ver palestra do Eng. Carlos Stevenson, 1934.

${ }^{26}$ No capítulo seguinte veremos com maior detalhe esta articulação de interesses entre proprietários de terra e a indústria de construção civil.
} 
era competência do município dotá-los de melhorias. Esta seria uma das questões que o Plano deveria resolver: a necessidade de torná-los efetivamente urbanos.

A urbanização das propriedades rurais e da promoção da indústria da construção civil exigiu da prefeitura altos investimentos na área urbana, fato que fez com que o poder local passasse a conviver com o déficit público, a partir dos anos 30. Este seria o último aspecto que comporia com a expansão e renovação urbana, a característica dessa segunda crise urbana: a gestão do déficit.

As mudanças no sistema tributário levaram a uma "desmunicipalização" dos impostos, devido ao desmantelamento da máquina política da "Velha República", promovendo restrições à autonomia ilimitada dos municípios. Em contrapartida, houve uma urbanização dos tributos no sentido de que cada vez com maior intensidade os tributos locais passam a depender mais decisivamente do porte das cidades e de seu grau de urbanização. A urbanização, portanto, está relacionada com a perda de competência sobre a produção geral, sobre a área rural, aumentando o peso das taxas locais e da tributação sobre as propriedades urbanas". ${ }^{27}$

As ações do governo federal anteciparam precocemente a questão do déficit publico; portanto, o que seria uma decorrência da promoção da reorganização territorial, com base na implantação das condições gerais da produção, naquele momento, passou a ser, também, motivador da política urbana a ser adotada.

A aprovação do plano foi retardada por quatro anos até ser consumada em 1938, por forças das circunstâncias políticas que envolveram o período Vargas, influenciando as relações de poder a nível local, ora destituindo as Câmaras Municipais, ora extinguindo as Comissões de Urbanismo.

O Plano de Melhoramentos Urbanos continha, segundo Badaró, cinco pontos importantes: 1) a proposta de uma estrutura viária que consagrou as radiais e introduziu perimetrais que, de espaço em espaço, circundariam a cidade; 2) o novo desempenho do centro histórico com grande preocupação estética e cívica, principais parâmetros a justificar o alargamento das ruas, a padronização das edificações particulares e a disposição dos edifícios públicos; 3) nas áreas verdes

27 "Ao nível nacional a industrialização, restringida pela estreiteza de sua base técnica e insuficiente capacidade financeira, não é capaz de implantar rapidamente o núcleo fundamental da indústria de bens de produção, que permitiria a autodeterminação do novo processo..., coube ao Estado, apesar de debilitado financeiramente pelo fraco desempenho do comércio exterior, assumir o papel de alargar os horizontes da acumulação. Para tanto, o sistema tributário foi reformulado e o aparelho estatal centralizado". Cf. Zimerman, op. cit., p. 4. Quanto aos tributos, houve um esvaziamento dos orçamentos municipais. As necessidades colocadas pela industrialização, a nível municipal, ficaram prejudicadas.

Revista de Direito da Cidade, vol. 08, no 2. ISSN 2317-7721 pp.587-610 606 
para instalação de grandes parques, novos conceitos para bairros residenciais, com jardins, escola, comércio e zoneamento próprios, além de estabelecer áreas preferenciais destinadas a instalação das indústrias ; 4) a criação de uma seção agrícola Municipal, para evitar que as áreas rurais fossem entendidas como áreas destinadas a futura ocupação urbana; 5) a recomendação de formação de comissões civis com caráter técnico, consultivo e de assessoramento à administração municipal.

A proposta apresentada por Prestes Maia evidenciou uma absoluta preferência pelo centro urbano, pois sua preocupação estava voltada para o recondicionamento físico do centro (renovação urbana). Avenidas no centro da cidade começaram a ser abertas mesmo antes do término do plano, ou melhor, da sua aprovação.

A formulação de uma política urbana passou a ser a pedra de toque da expansão e renovação urbana, como também a solução planejada da gestão do déficit público. A política urbana (via Plano) deu conteúdo e legitimidade ao papel da Prefeitura dentro daquele quadro de crise, privilegiando-a na tarefa que Ihe foi atribuída em relação à terra: a habilitação ${ }^{28}$ do solo urbano passou a ser priorizado pelas metas do Plano de Melhoramentos Urbanos.

\footnotetext{
${ }^{28}$ Entende-se por habilitação do solo urbano a capacidade e a competência atribuída à Prefeitura Municipal no que tange a produção do espaço urbano, transformando terra rural em urbana e na organização deste espaço no que se refere à elaboração de instrumentos de intervenção urbana como os códigos, leis de uso do solo, bem como as leis de zoneamento.
} 
MAPA 1

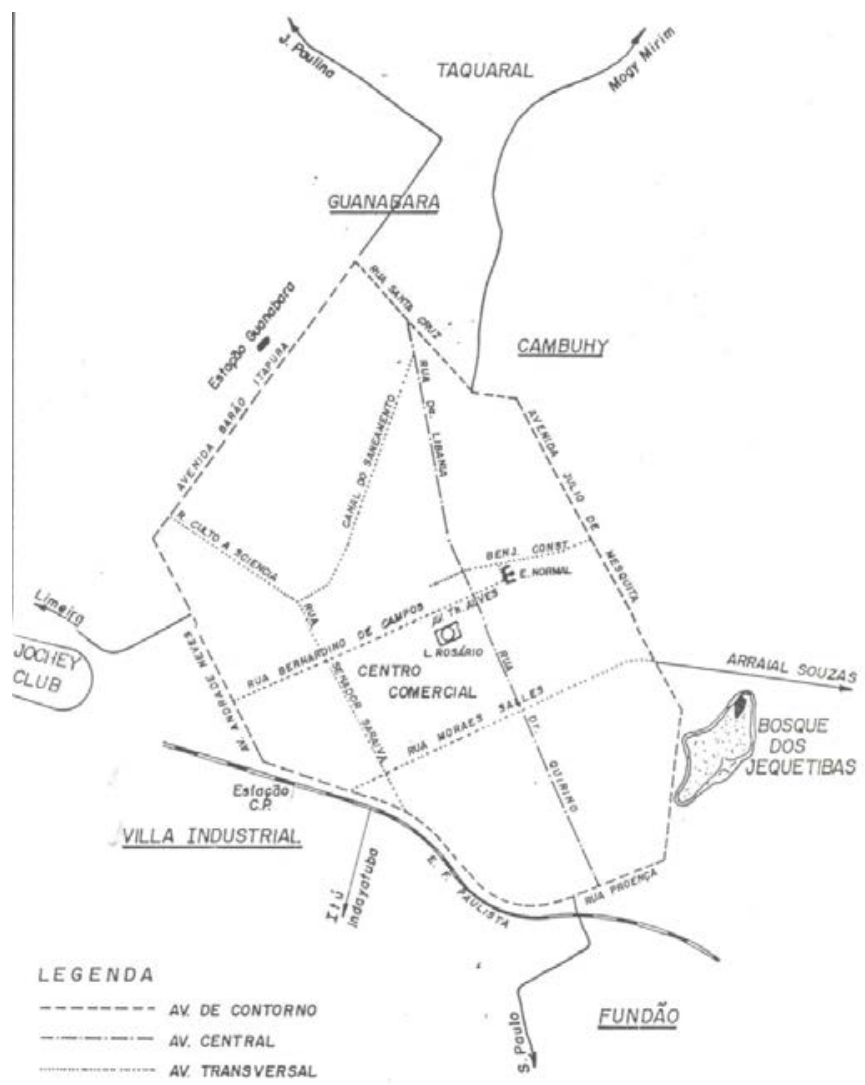

Fonte - Plano Viário - Engo. Carlos Sevenson - 1933. Apud. - BADARÓ, 1987, op. cit.

A municipalidade enfrentou duas ordens de problemas na execução das obras programadas para o centro: aqueles derivados da gestão do déficit e os decorrentes do processo de adensamento do centro. Foi a partir desse momento que a gestão do déficit foi colocada sob a lógica empresarial, submetendo o município e amplos setores da população urbana àquela lógica. Os setores mais pobres da população passaram a disputar com maiores dificuldades os serviços e os equipamentos coletivos. Assim, a abertura de ruas e avenidas, iniciada na década de 30 , se adequou a uma intensificação do processo de capitalização do centro urbano, via valorização dos seus imóveis, mesmo que se tivesse de recorrer a instrumentos extra-econômicos, como a erradicação de cortiços centrais ocorrida logo após a aprovação do Plano.

A expansão e a renovação urbana estavam articuladas de tal forma que o desenvolvimento de zonas de expansão inicia-se concomitantemente com a destruição de certas áreas centrais. Estes processos só foram possíveis porque a aprovação do Plano legitimava socialmente a 
intervenção em nome do desenvolvimento urbano. Desse modo, "o Estado assume o papel de mediador das contradições urbanas, permeando as relações de classe, intervindo no urbano e, desta forma, passou ser o promotor dos empreendimentos e serviços que ao capital não interessava promover, por não se apresentarem rentáveis à iniciativa privada". 29

A relação entre a urbanização e a industrialização, a partir dos anos 30, rompe com a divisão social (territorial) do trabalho, extremamente atrelada a uma economia monocultora e voltada para a exportação. Esta estrutura conferia ao campo um caráter autárquico e negava a cidade como espaço na divisão social (territorial) do trabalho. ${ }^{30}$

Quando a industrialização iniciou o seu processo de expansão, entre a segunda metade dos anos 20 e o final dos anos 40, promoveu, igualmente, uma autarcização das cidades, baseada numa indústria que ao "se instalar teve que simultaneamente instalar uma cidade, desde o fazer a casa do próprio operário (o que em muitos casos parecia um pouco o idílio entre capital e trabalho), e até uma complexa divisão social do trabalho no interior da própria fábrica". ${ }^{31}$

Nesse período, o Estado Brasileiro sofreu transformações para garantir as bases necessárias aos processos de industrialização, simultaneamente. Estas transformações passaram por processos cujo entendimento é indispensável para a compreensão da relação entre o Estado e a organização do espaço urbano: de um lado, o Estado passou a potenciar a acumulação industrial, através da sua intensa presença no espaço urbano e, de outro, interveio de maneira decisiva na relação entre capital e trabalho.

O Estado emergente em 1930 inaugurou uma nova etapa, apoiando-se num movimento de decisões centralizadas e concentradoras de poder. Contraditoriamente, a forma de organização federativa manteve os centros regionalizados de poder, gestando e gerenciando decisões cruciais.

\section{REFERÊNCIAS BIBLIOGRÁFICAS}

BADARÓ, Ricardo de S. Campos. O Plano de Melhoramentos urbanos (1934-1962). Dissertação de Mestrado, São Carlos, Escola de Engenharia de São Carlos, Universidade de São Paulo, 1986.

FARIA, Vilmar. Divisão social do trabalho especialização e crescimento urbano: o caso da Macrometrópole paulista. Xérox. 1978.

CARRION, Fernando. O desenvolvimento urbano de Quito entre suas crises urbanas mais recentes. In: Espaço \& Debates, Revista de Estudos Regionais e Urbanos, no 16, São Paulo, Cortez, 1982.

\footnotetext{
${ }^{29}$ Cf. Zimmerman, 1987, op. cit. P. 6.

${ }^{30}$ Oliveira, 1982, op. cit., p. 41.

${ }^{31}$ Oliveira, 1982, op. cit., p. 43.
} 
La Cuestion Urbana. 2. ed. Corrigiday aumentada. Siglo Veintiuno Editores, Espa $\pm a$, Argentina, 1974.

HARVEY, David. O processo urbano no capitalismo. Referencial para análise. Reproduzido da "International Journal or Urban anad Regional Research", vol. 2, №.1, 1978.

LESSA, Carlos. A crise urbana e o circuito imobiliário, seminário na Secretaria de Planejamento do Estado da Bahia. Salvador, mineo, s.d.

LIPIETZ, Alain. Alguns problemas da produção monopolista do Espaço Urbano, In: Espaço \& Debates, Revista de Estudos Regionais e Urbanos, out/dez. 1982, São Paulo, Cortez, 1982.

LOJKINE, Jean. A analise marxista do Estado. Revista de Estudos Regionais e Urbanos. Espaço \& Debates. Ano 1 no. 1, janeiro de 1981 (A). Ed. Cortez.

O estado capitalista e a questão urbana. Tradução de Estela dos Santos Abreu, São Paulo, Martins fontes, 1981(B).

OLIVEIRA, Francisco de. O Estado e o Urbano. Revista de Estudos Regionais e Urbanos. Espaço e Debates. Jul. 1982.

OTHAKE, Maria Flora Gonçalves. O processo de urbanização em São Paulo: dois momentos, duas faces. Dissertação de mestrado apresentada na PUC - SP, 1982.

RIBEIRO, Luiz César de Queiroz. Espaço Urbano, Mercado de Terras e produção da habitação, In: Solo urbano, tópicos sobre o uso da terra, Serie Debates Urbanos no.1, L.A. Machado da Silva (org.) Rio de Janeiro, Zahar, 1982.

SEMEGHINI, Ulisses Cidade e PACHECO, s/d, mimeo, 1985, p.30.

SEMEGHINI, Ulisses Cidade. Campinas (1860 - 1980). Agricultura, industrialização e urbanização. Dissertação de Mestrado, Instituto de Economia da UNICAMP. Campinas, 1988.

SILVA, Sergio. Expansão cafeeira e as origens da indústria no Brasil. São Paulo, Alfa - Omega, 1981.

STEVENSON, Carlos W. Conferência acerca do urbanismo na cidade de Campinas. 17/11/1933, Rotary Club de Campinas, Campinas, Linotypia da Casa Genoud, 1934.

ZIMMERMANN, Gustavo. Finanças públicas municipais: o caso de Campinas. Dissertação de mestrado, Universidade Estadual de Campinas, 1987.

Trabalho enviado em 28 de janeiro de 2016.

Aceito em 03 de abril de 2016. 